\title{
A Survey on Workplace Violence Experienced by Critical Care Physicians
}

\author{
Nadikuda Sunil Kumar ${ }^{1}$, Kartik Munta ${ }^{2}$, J Raj Kumar ${ }^{3}, \mathrm{~S} \mathrm{Manimala} \mathrm{Rao}^{4}$, M Dnyaneshwar $^{5}$, Yogesh Harde ${ }^{6}$
}

\begin{abstract}
Introduction: Workplace violence (WPV) has been defined as, "violent acts including physical assault and threats of assault directed toward personnel at work or on duty". Healthcare staff are at highest risk of WPV among the professionals and it is more common among the critical care services. Prevalence of WPV among doctors all over the world is around $56-80 \%$ and in Indian scenario, it is around $40.8-75 \%$. There is scarcity of studies on WPV among doctors from India. To our knowledge, this is the first of its kind survey conducted to know about the incidence of WPV amongst critical care physicians in India.

Materials and Methods: This survey was conducted after taking due ethical committee clearance amongst critical care physicians attending a critical care conference. The purpose of the study was informed to the participants and a pretested, self-administered, semi-structured questionnaire was distributed among them for their voluntary and anonymous response.

Results: Out of 160 delegates who were given the questionnaire, 118 responses were collected and their forms were analyzed. Maximum responses (84\%) received were of age group 20-40 years. Seventy-two percent respondents experienced WPV during their work hours. Most common type of violence reported was verbal violence (67\%). Sixty-five percent respondents reported that poor communication was the leading cause of WPV. Due to WPV, most of the respondents (60\%) had to change their place and pattern of work. Proper communication (76\%) was the most common measure among multiple measures suggested by respondents for avoiding WPV. Eighty-three (98\%) respondents opined that conflict management should be part of regular curriculum in medical education.

Conclusion: Improving the communication skills amongst critical care physicians, teaching doctors about conflict management in their regular curriculum of medical education, spreading awareness in public about patient rights and taking initiatives in propagating an idea to "Fight against the diseases and not against the doctors" are the key measures to combat WPV.
\end{abstract}

Keywords: Critical care physicians, Communication, Verbal violence, Workplace violence

Indian Journal of Critical Care Medicine (2019): 10.5005/jp-journals-10071-23202

\section{INTRODUCTION}

Violence is a style of communication and conflict resolution, physicians are treated no different from anybody else. ${ }^{1}$ Workplace violence (WPV) has been defined as "violent acts including physical assault and threats of assault directed towards personnel at work or on duty". ${ }^{2}$ As per OSHA (Occupational safety and health administrative), healthcare staff are at highest risk of WPV among the professionals, with a four-fold high likely chance to get injured and require break from work due to WPV. ${ }^{3-5}$

WPV in hospitals is growing as a global pandemic. ${ }^{6,7}$ Approximate incidence of WPV among doctors all over the world is around $56-80 \% .{ }^{4,8}$ Actual extent of the problem is estimated to be substantially higher as the problem remains grossly neglected and under reported.

In developing countries like India WPV has major impact on health sector as this is one of the growing fields, where health expenses are paid by individuals and in recent past, it has been increasing exponentially. Prevalence of WPV amongst doctors in Indian scenario is around $40.8-75 \% .{ }^{9,10}$ Violence is more common among the critical care services after psychiatry as they deal with people in highly stressful, emotional and anxious states. $4,5,11,12$ Verbal abuse is the most common type and patient visitors are the most common cause of WPV in hospitals. ${ }^{13}$

WPV is a new upcoming occupational hazard and has significant long lasting effects on healthcare providers. ${ }^{14}$ There exists a dearth of studies on this problem regarding perception of the healthcare

\begin{abstract}
${ }^{1-6}$ Department of Critical Care Medicine, Yashoda Multi-Speciality Hospital, Somajiguda, Hyderabad, India

Corresponding Author: Nadikuda Sunil Kumar and S Manimala Rao, Department of Critical Care Medicine, Yashoda Multi-Speciality Hospital, Somajiguda, Hyderabad, India, Phone: +91-9441286737, e-mail: sunildockmc@gmail.com
\end{abstract}

How to cite this article: Kumar NS, Munta K, Kumar JR, Rao SM, Dnyaneshwar M, Harde Y. A Survey on Workplace Violence Experienced by Critical Care Physicians. Indian J Crit Care Med 2019;23(7):295-301.

Source of support: Nil

Conflict of interest: None

providers particularly in young doctors. It remains grossly under researched in India. ${ }^{4,11}$

The purpose of the study is to draw attention toward the issue of violence against critical care physicians, reveal the dimensions of such violence and highlight ill effects of WPV on personal life of doctors. The study also contributes to the measures to be undertaken in addressing this issue and potential recommendations for its prevention in field of "critical care medicine" in India. To our knowledge, this is the first of its kind study conducted on critical care physicians on WPV in India.

\section{Materials and Methods}

After taking due ethical committee clearance, the survey was conducted among the critical care physicians attending a critical

() The Author(s). 2019 Open Access This article is distributed under the terms of the Creative Commons Attribution 4.0 International License (https://creativecommons. org/licenses/by-nc/4.0/), which permits unrestricted use, distribution, and non-commercial reproduction in any medium, provided you give appropriate credit to the original author(s) and the source, provide a link to the Creative Commons license, and indicate if changes were made. The Creative Commons Public Domain Dedication waiver (http://creativecommons.org/publicdomain/zero/1.0/) applies to the data made available in this article, unless otherwise stated. 


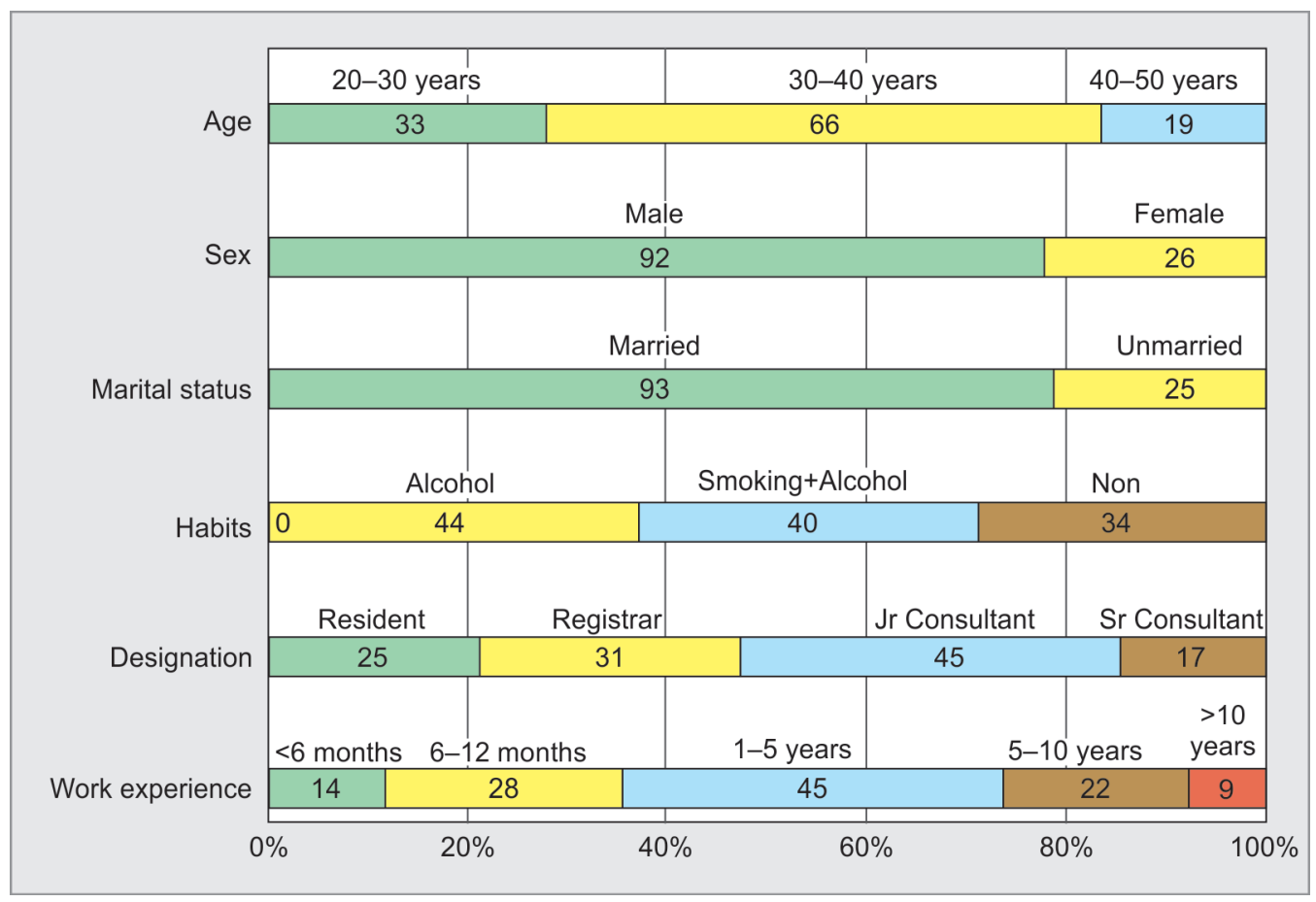

Fig. 1: Demographic data

care conference. Purpose of the study has been informed to the participants and a pretested, self-administered, semi-structured questionnaire was framed under broad sections (mentioned below). The questionnaire was distributed at the registration desk for their voluntary and anonymous response, assurance was given to them concerning confidentiality and responses were collected into a drop box.

Questionnaire details: A total of 30 questions were framed and divided into five main domains.

1. Demographic data - Demographic details with ICU working experience.

2. ICU infrastructure - Type of ICU, facilities available and policies implemented.

3. Violence episode details - Number and type of violence episodes.

4. Violence sequelae - Response of the victim and authorities toward the violence episode.

5. Retrospective analysis - Impact and measures to overcome the violence episode.

Standard definitions adopted from WHO were used to define the types of violence, according to which verbal violence was defined as a negative defining statement told to the victim or about the victim, or by withholding any response, thereby defining the target as nonexistent. Similarly physical violence was described as the use of physical force against another person or group that results in physical, sexual or psychological harm. This includes beating, kicking, slapping, stabbing, shooting, pushing, biting and pinching. ${ }^{4}$ After collecting the responses, data were entered into Microsoft Excel sheet and analyzed in percentage responses.

\section{RESULTS}

Out of 160 delegates who were given the questionnaire, 118 responses were collected and analyzed.

\section{Demographic Data}

Maximum respondents were in the age group of 20-40 years $(99$ $84 \%)$, with a working experience of less than five years in the field of critical care medicine 87 (74\%). Of all the respondents, (92; 78\%) were males and 26 (22\%) were females. Ninety-three (79\%) respondents were married (Fig. 1).

\section{ICU Infrastructure}

Maximum respondents were from private hospitals i.e. 92 (78\%), mostly from medical ICU's i.e. $53(45 \%)$ and $47(40 \%)$ respondents were from mixed ICU's. Median number of beds were 15 , with a nursing ratio around $1: 2(53 ; 45 \%)$ to $1: 3(45 ; 38 \%)$. Most of the ICU's $(105 ; 89 \%)$ had 24 hours security cover, performed counseling (114; $97 \%$ ) and practice consent protocols (115; 97\%) (Fig. 2).

\section{Violence Episode Details}

Among 118 respondents, 85 (72\%) experienced WPV during their ICU work hours. Maximum episodes were experienced during night times when working staff was less. Most common type of violence was verbal 57 (67\%) and in maximum episodes patient visitors were the cause of violence 75 (88\%). Most of the events i.e. 70 (85\%) were reported to concerned authorities and the response was non-satisfactory according to 45 (53\%) respondents (Figs 3 and 4).

\section{Causes of Violence}

Poor communication $(65 \% ; 55$ out of 85 ) was the leading cause of WPV. Billing related disputes were $27 \%$ (23/85), dissatisfaction regarding medical services were $21 \%(18 / 85)$ among other major causes. Among respondents, only $17(20 \%)$ had prior knowledge and experience of managing such WPV episodes (Figs 4 and 5).

\section{Effects of Violence}

Due to WPV most of the respondents had to change their place and pattern of work $60 \%$ (51/85), and there were loss of working hours 


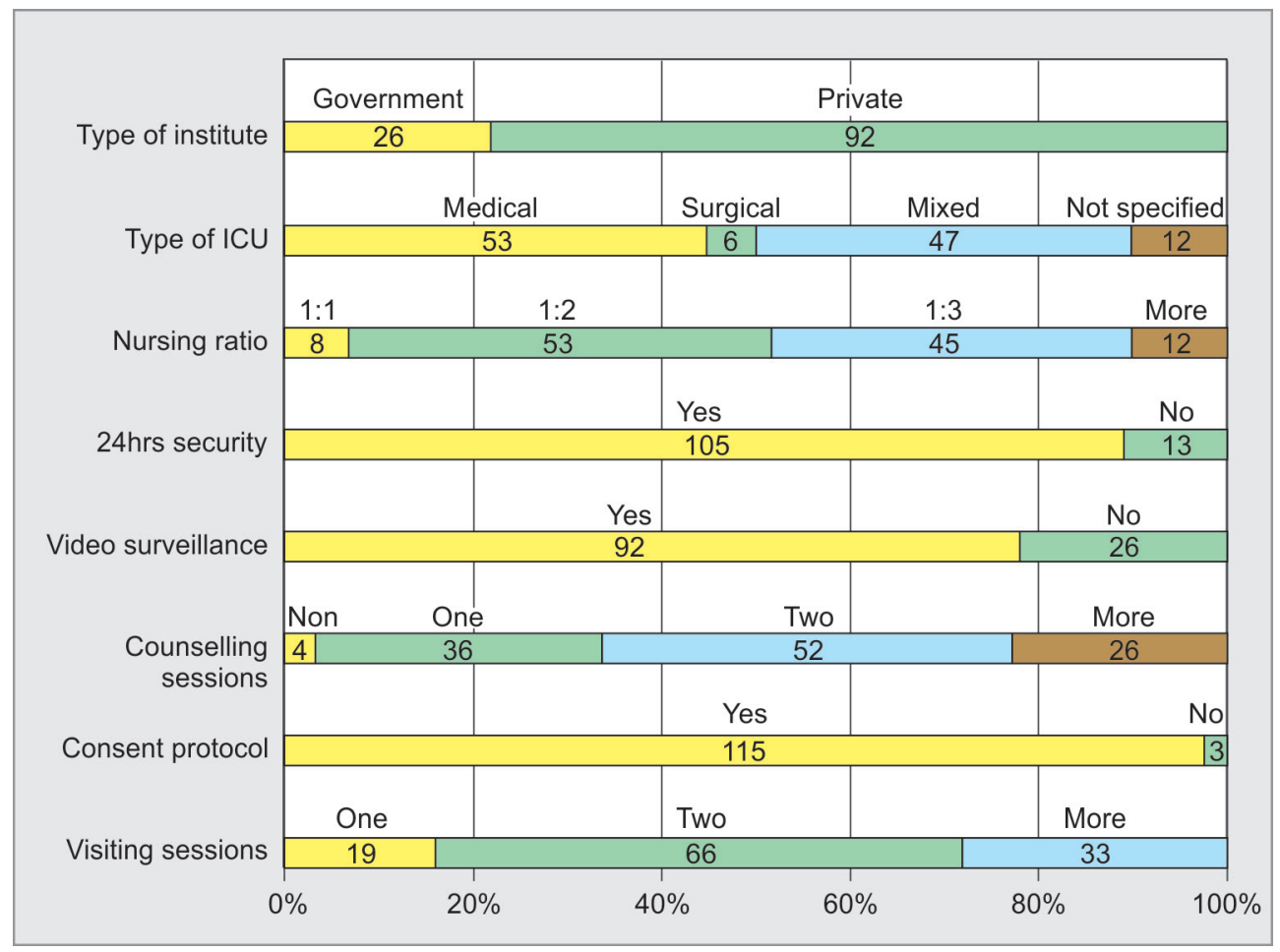

Fig. 2: ICU Infrastructure

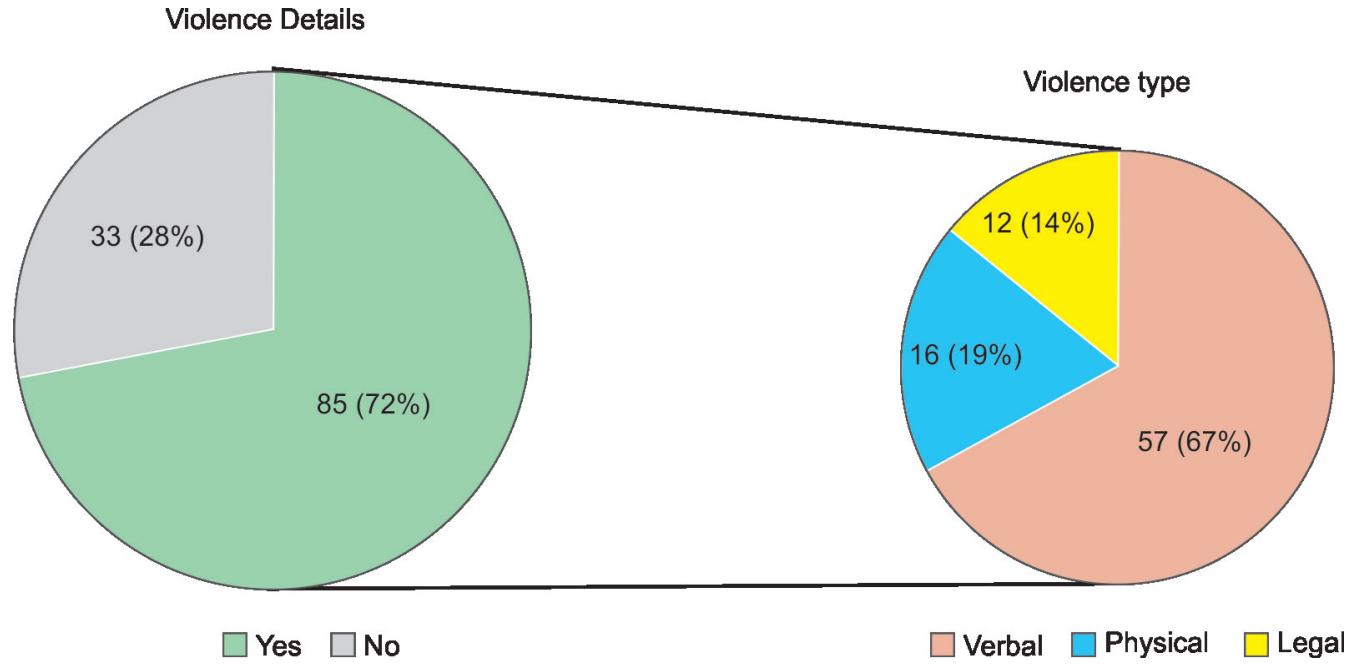

Fig. 3: Violence details

$28 \%(24 / 85)$. The respondents opined that it had affected their education $26 \%(22 / 85)$ and had profound psychological impact $23 \%(20 / 85)$ on them (Fig. 6).

\section{Remedial Measures Suggested}

Most of the respondents $70 \%(60 / 85)$ felt that maximum number of episodes (50-70\%) which happened were avoidable. Remedial measures like proper communication $76 \%(65 / 85)$, by improving security 49\% (42/85), infrastructure 47\% (40/85), ensuring vigilant monitoring $29 \%$ (25/85), increasing responsibilities of the hospital authorities $29 \%(25 / 85)$ were suggested by the respondents for avoiding WPV.

Ninety-eight percent (83/85) respondents felt that conflict management should be a part of their regular curriculum of medical education and conflict management teams should be formed in hospitals to avoid, advise, support and overcome episodes of WPV (Figs 4 and 7).

\section{Limitations of the Study}

Survey was conducted amongst critical care physicians attending a critical care conference hence generalization of the findings cannot be done. Participant's reported violence, relevant exposure which had no time frame. Hence there is a potential for selection and recall bias. Maximum respondents were young and inexperienced, which may lead to biased results. Despite these limitations our study has provided an insight into the incidence of WPV among critical care physicians, highlighting the potential risk factors, impact on their personal life and the preventive measures to be taken to avoid such episodes. 


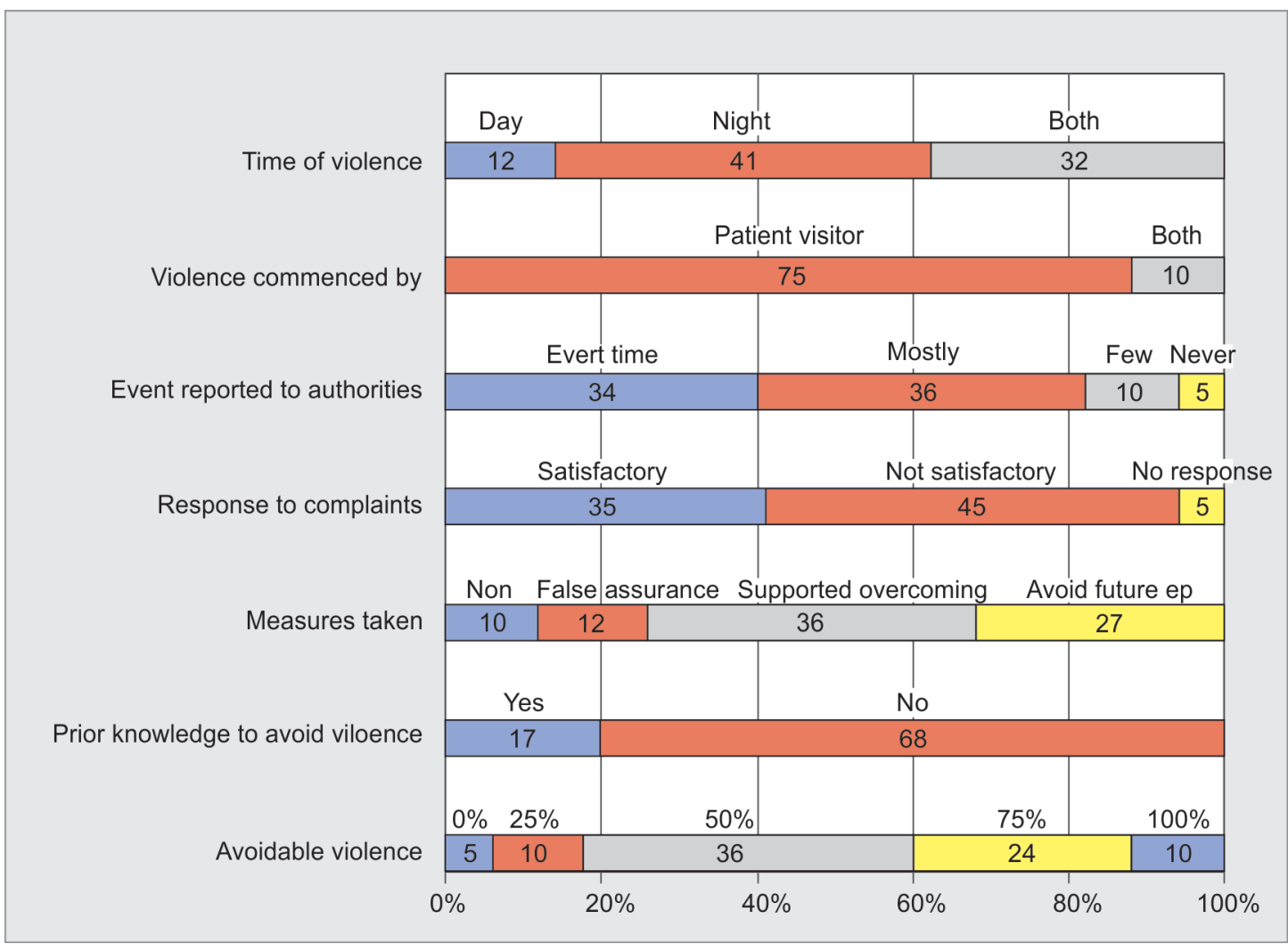

Fig. 4: Violence details and sequela

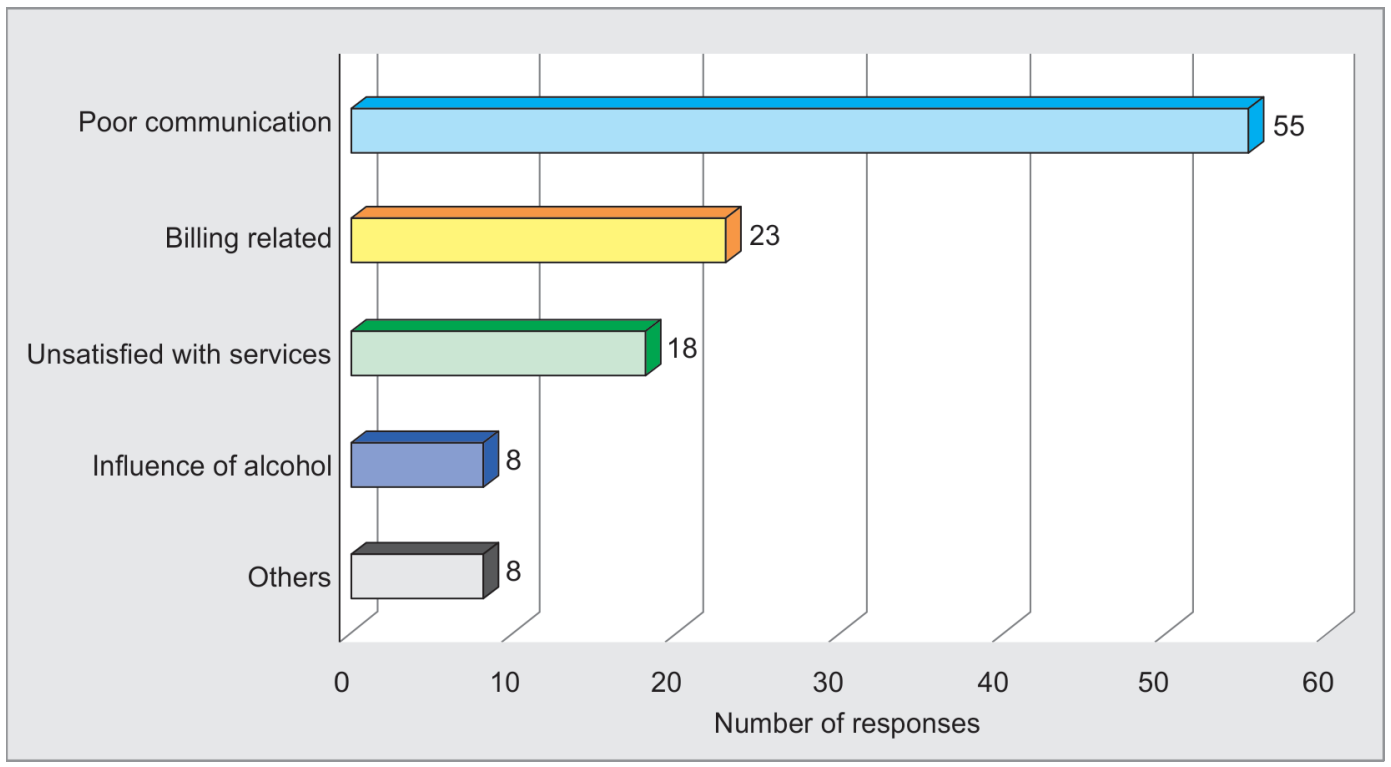

Fig. 5: Causes of violence

\section{Discussion}

Annual incidence of WPV is four times more in healthcare (8 serious cases per 10,000 full time employees) as compared to all other professions ( 2 per 10,000$)^{2,8}$ and working in healthcare institution is 16 times more risky than working in another business. Nurses working in psychiatric department are third group of professionals most exposed to violence after prison guards and police officers. ${ }^{12}$
During 1980-1990, hundred healthcare workers died as a result of violence in USA; a survey in 170 university hospitals over 5 years revealed $57 \%$ of all employees in emergency department had been threatened with weapon. ${ }^{15,16}$ In 2008, a survey conducted on 600 doctors of Britain showed 1/3rd to be victims of violence and half among them did not report the incident. ${ }^{7}$ In Israel, 70\% of emergency department physicians and $90 \%$ of supporting staff working had experienced violence, amongst them verbal abuse 


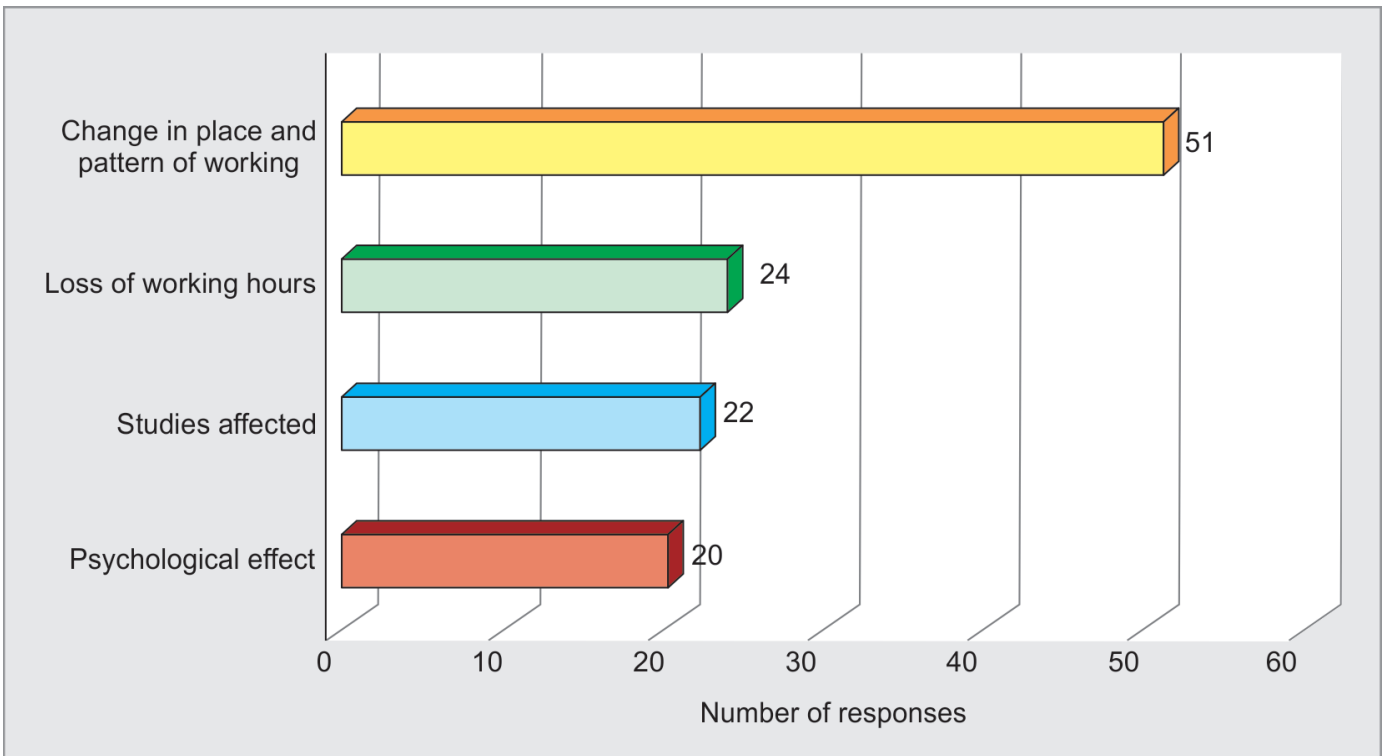

Fig. 6: Impact of violence

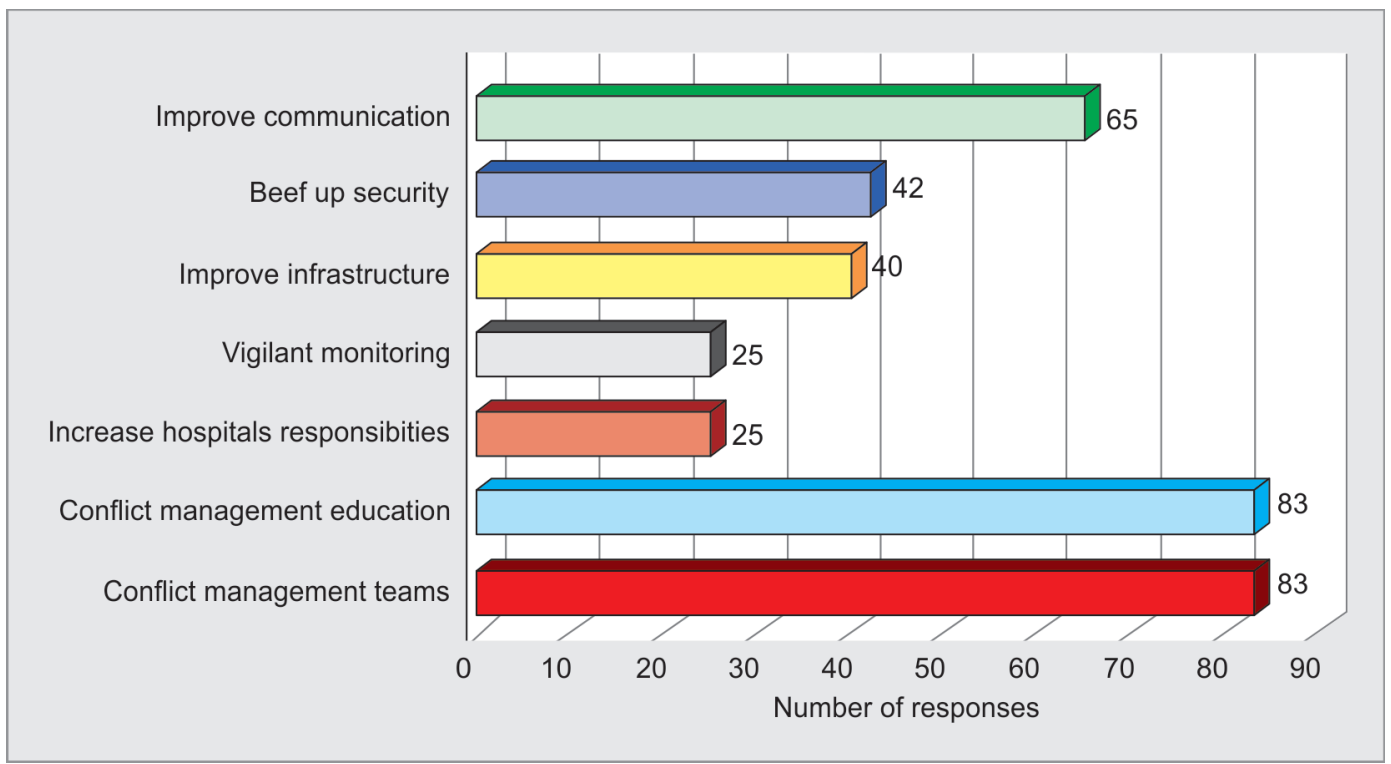

Fig. 7: Remedial measures

was most common. ${ }^{7}$ In China, incidence of non-physical violence is $68-76 \%$ and physical is around $8-35 \% .^{6}$ In Pakistan incidence of WPV in doctors is around $74 \% .^{17}$ Factors differ from developed to developing countries where education and low socioeconomic status play a major role along with poor infrastructure. ${ }^{6}$

Indian Medical Association has reported that $75 \%$ doctors had experienced violence and $82.7 \%$ had profound work stress. ${ }^{7,14,18}$ Almost half of the violent incidents occur in critical care units, wherein the intensivists working here face such episodes almost daily. Such incidents are more common in government hospitals where workforce is less and infrastructure is poor. ${ }^{19}$ Our study has shown an incidence of WPV to be $72 \%$ amongst which $22 \%$ respondents were from government sector of whom maximum experienced WPV.

In the Anglo and anglicized regions of the world .i.e. United Kingdom, Ireland, New Zeland, Australia, United States and Canada, physical violence is reported more commonly. Bullying is common in the Middle East. ${ }^{8}$ Very few studies have been undertaken in Asia, Indian subcontinent, out of which recent studies are from China. ${ }^{18-20}$ Most common type of violence is verbal abuse and least common is physical violence among all departments in Indian context. ${ }^{4,5,21}$ Most incidents occurred during morning or night hours and took place in hospital premises. ${ }^{4}$ Highest rate of incidents were reported in the evening between $4-8$ pm. ${ }^{12}$ In our study, verbal abuse (67\%) was most common type of violence. WPV was most commonly initiated by patient visitors ( $88 \%$ ) during night times (48\%). Whereas $38 \%$ experienced it both day and night.

Healthcare WPV is a serious emerging threat to the patientdoctor mutual relationship all over the world. It has evolved in to a prominent challenge for medical profession. ${ }^{4,14}$ Most of the studies done worldwide on WPV proved, poor communication to be the most common cause of violence (Table 1). A study conducted in public hospital in Mumbai, India, showed that most doctors and almost all patients felt that many problems would be 
Table 1: Causes, effects and remedial measures of workplace violence

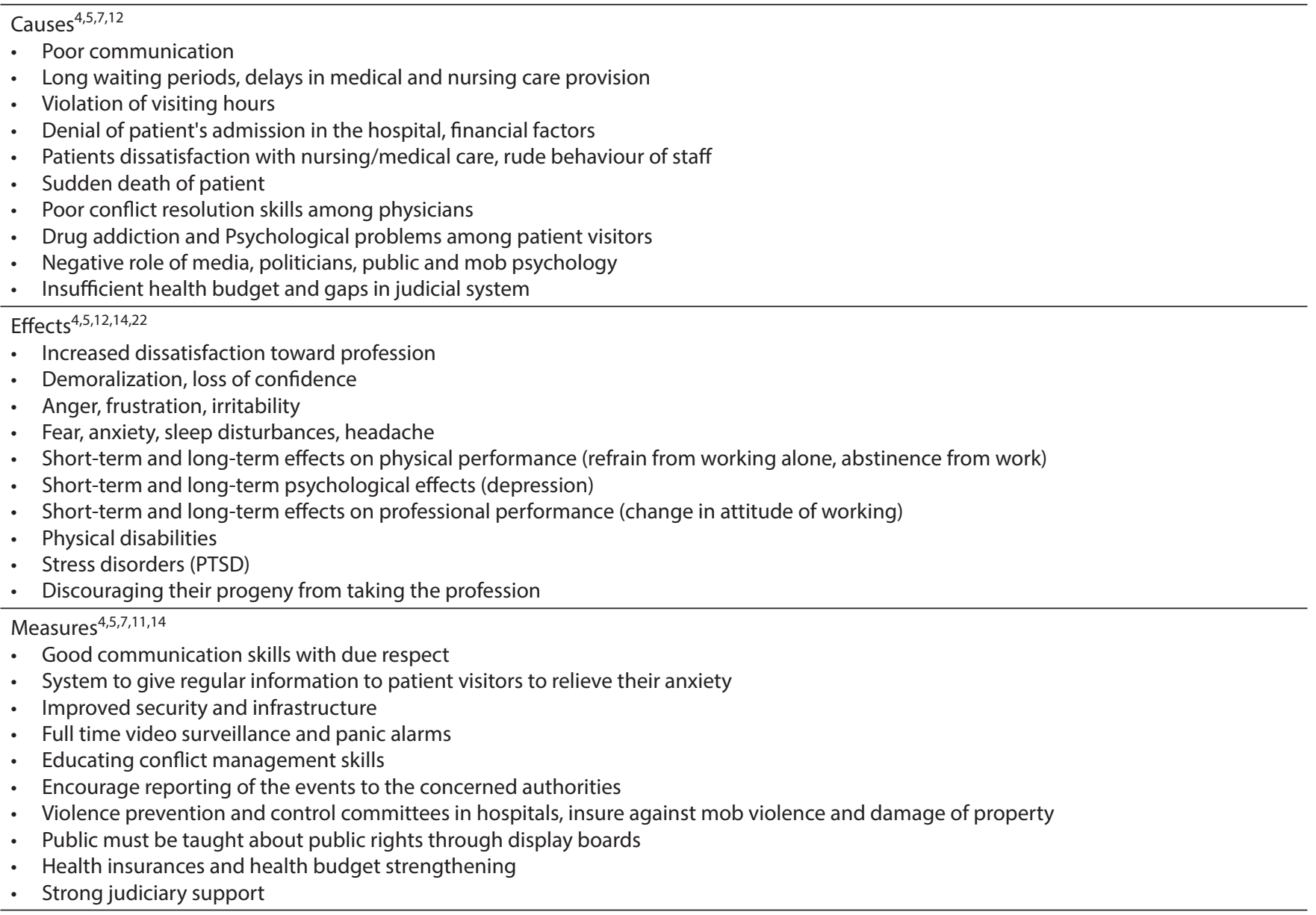

resolved if patients were treated with more respect. Residents are usually entrusted with delicate tasks as breaking the bad news or events happening in operating or emergency room. Seniors should deal with serious issues like breaking the bad news and explaining the untoward events happening in hospitals. ${ }^{23,24}$ In our study, poor communication (65\%), billing related issues (27\%) and dissatisfaction with services (21\%) were the common causes of WPV among respondents. Amongst the respondents only $20 \%$ had prior knowledge and experience of handling WPV episodes.

WPV has a negative impact on the physical and psychological well being. ${ }^{5}$ WPV affects the health of the doctor in long run via psychological stress, which leads to sleep disturbances and quality of care. ${ }^{4,14}$ A study conducted in Canada showed $73 \%$ respondents had fear of treating patients due to WPV. Seventy-four percent reported reduced job satisfaction and $67 \%$ had a job change ${ }^{22}$ (Table 1). In our study, $60 \%$ respondents reported change in their place and pattern of working, $28 \%$ lost working hours, $26 \%$ had effect on their studies and $23 \%$ had psychological impact (Fig. 6).

Though doctors are the victims of WPV, society as a whole has to pay the cost due to change in the attitude of doctors toward medical profession and patients, which gets transmitted horizontally and vertically. ${ }^{14}$ A study conducted in 2002 by Jiao et al. revealed only $11 \%$ Chinese doctors wanted their children to join medical profession, but in 2011 this further reduced to $7 \%$, as a consequence recruitment and retention of doctors have become major challenge for the Chinese healthcare system. ${ }^{25}$ Similar sentiments are being echoed in Indian subcontinent also. ${ }^{19,26}$

Violence is routinely under reported in health sector because the perception among the healthcare workers is that, violence is an expected part of their job and fear the response they may receive when such events are reported. In the present study a meager $40 \%$ reported WPV events to the concerned authorities every time.

A cross sectional study in China concluded three types of remedial measures for WPV- individual, organisational and social training combined with legal and security measures. ${ }^{27}$ It has been emphasized that lack of professional training for handling violent incidents may be the reason for less experienced professionals to become victims. Looking for indicators of violent behavior such as Staring looks, Tone and violence in voice, Anxiety, Mumbling, and Pacing (STAMP behavior) are few predictors ${ }^{7}$ (Table 1). In our study, respondents felt communication(76\%) plays an important role, and improving security (49\%) and infrastructure devolopment (47\%) would help. Other measures advised were vigilant management and increasing hospital administration responsibility in avoiding such acts (Fig. 7).

Physical exercise, sleep, company of family, friends and colleagues were the most useful coping strategies. ${ }^{22}$ Doctors who were given lessons in communication could manage most potentially violent situations. ${ }^{23}$ Medical education and CME's should include this topic giving appropriate emphasis. ${ }^{28}$ Indian 
studies in the past emphasized on legal measures, security beef up and increasing number of doctors and other staff have been recommended. ${ }^{4,5}$ Only installing security personnel may not yield long lasting results, in fact it may worsen some situations. ${ }^{6}$ In our study almost $98 \%$ advised that conflict management education should be the part of medical education curriculum and conflict management teams to be formed in hospitals (Table 1 and Fig. 7).

According to the OSHA WPV can be prevented or the risk at least minimized, when employers take the necessary precautions. OSHA advocated an interdisciplinary approach to WPV prevention and implementation of a "Zero tolerance policy" to help achieve goal of resolving WPV. Uploading videos for public education, forming and empowering hospital violence prevention and control committee, improving doctor-patient mutual relations, improving security and using hi-tech security measures have been few of their suggestions. ${ }^{14}$

Few hospitals in UK used a "Zero tolerance policy" with green, yellow and finally red warning cards according to the type of violence which penalized aggressive behavior by transfer to another hospital. ${ }^{11,19}$ Nineteen states in India have dedicated nodal agencies and institutions in handling incidents of WPV. ${ }^{7}$ States like Odisha, Maharashtra and Kerala have passed laws for punishment of WPV for medical services in recent past. ${ }^{4,13}$ To prevent violence in hospitals in India, "Hospital Protection Act" was passed in 2008 where persons engaged in violence are liable to be imprisoned for 3-10 years under legislation. ${ }^{12}$

\section{CONCLUSION}

Improving the communication skills among doctors is the need of the hour, this can be improved by including conflict management in regular curriculum of medical education and conducting regular CME programs. As WPV is highest in emergency and critical care department, conflict management training should be more stressed while training physicians in these departments. Increasing the responsibilities of hospital administration, enhancement of security in the night times, spreading awareness in public about patient rights, strengthening the medical insurance and judiciary system play an integral role in curtaining this menace in India. Let's all spread the word to "Fight against the diseases and not against the doctors".

\section{ACKnOWLedgment}

We are very thankful to ISCCM Hyderabad Chapter for encouraging and supporting us to conduct this survey.

\section{References}

1. Morrison JL, Lantos JD, Levinson W. Aggression and violence directed towards physicians. J Gen Intern Med, 1998;13:556-561.

2. Occupational Safety and Health Administration(OSHA) US Dept of Labour. Fact sheet: workplace violence in healthcare, 2015. Available at: https://www.osha.gov/dsg/hospitals/workplace violence.html.

3. Warren B. Workplace violence in hospitals: safe havens no more. Journal of Healthcare Protection Management, 2011;27(2):9-17.

4. Anand T, Grover S, Kumar R, Kumar M, Ingle GK. Workplace violence against resident doctors in a tertiary care hospital in Delhi. Natl Med J India 2016;29:344-348.
5. Kumar M, Verma M, Das T, Pardeshi G, Kishore J, Padmanandan A. A study of workplace violence experienced by doctors and associated risk factors in a tertiary care hospital of South Delhi, India. J Clin Diagn Res 2016;10:LC06-LC10.

6. Syed MMA. Violence against healthcare professionals: are we looking for the peaceful truce?. Int J Stud Res 2016;6(1):12.

7. Nagpal N. Incidents of violence against doctors in India: Can these be prevented?. Natl Med J India 2017;30:97-100.

8. Nelson R. Tackling violence against health-care workers. Lancet. 2014;383(9926):1373-1374.

9. Bal A. A doctor's murder. Issues in Medical Ethics. 2001;9-39.

10. Balamurugan G, Jose TT, Nandakumar P. Patients' violence towards nurses: A questionnaire survey. Int J Nursing 2012;1:1-7.

11. Lynch J, Appelboam R, McQuillan PJ. Survey of abuse and violence by patients and relatives towards intensive care staff. Anaesthesia. 2003; 58(9), 893-899.

12. Kaplan B, Pişkin RE, Ayar B. Violence against Healthcare Workers. Med J Islamic World Acad Sci. 2013; 21(1): 4-10.

13. Ori J, Devi NS, Singh AB, Thongam K, Padu J, Abhilesh R. Prevalence and attitude of workplace violence among the post graduate students in a tertiary hospital in Manipur. J Med Soc 2014;28:25-28.

14. Joshi SC, Joshi R. Doctor becomes a patient: a qualitative study of healthcare work place violence related perception among junior doctors working in a teaching hospital in India. Int J Community Med Public Health 2018;5: 1775-1786.

15. Goodman RA, Jenkins EL, Mercy JA. Workplace-related homicide among healthcare workers in the United States, 1980 through 1990. JAMA 1994;272:1686-1688.

16. Kuhn W. Violence in the emergency department: Managing aggressive patients in a high-stress environment. Postgrad Med J 1999;105:143-148, 154.

17. Imran N, Pervez MH, Farooq R, Asghar AR. Aggression and violence towards medical doctors and nurses in a public healthcare facility in Lahore, Pakistan: A preliminary investigation. Khyber Med Univ J 2013;5:179-184.

18. Ambesh P. Violence against doctors in the Indian subcontinent: A rising bane. Indian Heart J. 2016;68(5):749-750.

19. Kapoor MC. Violence against the medical profession. J Anaesthesiol Clin Pharmacol 2017;33:145-147.

20. Violence against doctors: Why China? Why now? What next? Lancet. 2014;383(9922):1013.

21. Aydin B, Kartal M, Midik O, Buyukakkus A. Violence against general practitioners in turkey. J Interpers Violence 2009;24:1980-1995.

22. Fernandes CM, Bouthillette F, Raboud JM, et al. Violence in the emergency department: a survey of healthcare workers. CMAJ. 1999;161(10):1245-1248.

23. Madhiwalla N, Roy N. Assaults on public hospital staff by patients and their relatives: an inquiry. Indian Journal of Medical Ethics, [S.I.], v. 3, n. 2, p. 51, nov. 2016. ISSN 0975-5691.

24. Pane GA, Winiarski AM, Salness KA. Aggression directed toward emergency department staff at a university teaching hospital. Ann Emerg Med 1991;20:283-286.

25. Jiao M, Ning N, Li Y, Gao L, Cui Y, Sun H, et al. Workplace violence against nurses in Chinese hospitals: a cross-sectional survey. BMJ Open 2015;5:e006719.

26. Bawaskar HS. Violence against doctors in India. Lancet. 2014;384(9947):955-956.

27. Zhao S, Liu H, Ma H, Jiao M, Li Y, Hao Y, et al. Coping with workplace violence in healthcare settings: social support and strategies. Watterson A, ed. Int J Environ Res Public Health. 2015;12(11):1442914444.

28. Vorderwülbecke F, Feistle $M$, Mehring $M$, Schneider A, Linde $\mathrm{K}$. Aggression and violence against primary care physicians - a nationwide questionnaire survey. Deutsches Ärzteblatt Int. 2015;112(10):159-165. 